THURSDAY, JULY 26, 1888.

\section{SCIENTIFIC ASSESSORS IN COURTS OF JUSTICE.}

PUBLIC attention has lately been called, by various incidents, to the system under which the trial of scientific cases, and especially those in which the respective rights of rival inventors are involved, is at present conducted in courts of justice. Last week Mr. Justice Kay decided a case in which the Edison-Swan United Electric Company were plaintiffs, which lasted twenty-one whole days, or about one-tenth of the legal year ; and it is possible that it may occupy very much more time in the Court of Appeal, where every day is equivalent to three days in ordinary courts, because three judges sit here, and again in the House of Lords, if the litigants decide to proceed to extremities, as they very frequently do in cases of this magnitude and importance. At the same time, $\mathrm{Mr}$ : Justice Kekewich was engaged in trying another large electric patent case; the Court of Appeal had a similar case occupying it for several days, in the course of which Lord Justice Cotton, who presided, animadverted in somewhat severe terms on the length to which such cases are allowed to run. His Lordship, with the concurrence of the two Lords Justices who sat with him, attributed this to the manner in which counsel spun out their arguments, and urged more brevity and conciseness. Whatever may have been the circumstances in the case to which the Lord Justice adverted, it is certain that the addresses of the eminent counsel engaged in the Edison-Swan case were not responsible for the twenty-one days which it occupied before Mr. Justice Kay-not including seven or eight days for experiments ;--by far the greater part of this time was occupied in hearing the contradictory and conflicting evidence of a score of scientific men, many of the greatest eminence, on the points in dispute between the parties. With these points we have absolutely nothing to do here. It is sufficient to say that the case involved the investigation and decision of matters of the utmost complexity respecting the applications of recent electrical discoveries to lighting, and also some obscure questions in the history of these applications. All these exceedingly complicated and difficult questions were tried before an eminent judge, who, as he said himself at the commencement of his judgment, "has not had the requisite scientific training." It was, in fact, necessary to begin by instructing the judge in the elements of electrical science; the propositions which scientific men accept as truisms, or as common knowledge in discussions amongst themselves, had here to be gone over $a b$ initio in order to inform the judge's mind respecting the $\mathrm{A} \mathrm{B} \mathrm{C}$ of the problem which he had to solve. As to Mr. Justice Kay's success in the task of acquiring this information, we are quite willing to accept the opinion of one of the leading electrical papers, which says that "the manner in which the judge grasped the bearing of the technical evidence has been the subject of remark amongst everyone present in court."

We have no doubt that a judge, with his trained and experienced mind, would make a very apt pupil ; but the process of obtaining knowledge, even in such cases, is not always a very smooth or pleasant one. It is trying Vol.. XXXVIII.-No. 978. to the calmest and most equable mind to be compelled constantly to reconsider information acquired with care and difficulty, to find the views inculcated by one eminent man of science totally contradicted by another equally eminent. It is not surprising that in the maze of conflicting opinions Mr. Justice Kay was unable of his own knowledge to find his way. We reproduced a painful incident in our columns at the time it occurred, with the view of exhibiting to our readers one of the evils of the present system for trying complicated cases, although the circumstance that the case was then sub judice precluded us from offering any comment on it. We did this with a view of suggesting, also, that whoever was wrong-the judge or the expert witness-a matter which it did not concern us to inquire into-it is not in the interests of science that scientific men of reputation should put themselves in the position of advocates, thus rendering such treatment possible. Judges are only human, and, so long as men with no scientific training are left to bear unaided the burden of trying cases like that in which the Edison-Swan Company were plaintiffs, with their conflicting evidence, their authoritative opinions one way flatly contradicted by equally authoritative opinions the other, their masses of facts on subjects unfamiliar to the judge, so long must scientific men who are concerned in such cases expect unpleasant rencontres of this description either with the perplexed and worried judge or with the counsel on one side or the other. To be a witness at any time in a court of justice is not pleasant ; it is an experience we have all to go through, at one time or another, with more or less resignation, supported by the consciousness that we are doing our duty as citizens and aiding the course of justice. But to be a witness in a scientific case on a subject to which you have devoted your life, and with regard to which you have obtained a position of authority, it may be, amongst your fellows who are, of all men in the world, the most capable of judging, and to be compelled to undergo cross-examination of the usuai type at the hands of a gentleman who made up his few meagre and jejune facts on the subject from his brief the night before, and who will forget all he knew by the next night-this is hard indeed. But we cannot see how men of science can get out of these inconveniences and unpleasantnesses any more than any other class of the community, so long as the trials of these cases are in the hands of men who know nothing of science, and who have no regular and systematic means of obtaining aidjudicial aid, that is-from those who do.

Lawyers appear to be as discontented with the present system as men of science have reason to be. The principal legal paper went so far the other day as to suggest the formation of a special court for the trial of patent cases. These have increased so much of recent years, consequent on the vast increase of scientific discoveries and their practical applications to the business of life, that the old machinery is no longer adequate to deal with the new situation. Other litigants suffer in their business and pockets ; the courts become congested, and the judicial business of the country is seriously impeded. The present arrangements can be satisfactory to no one, except, perhaps, to the few lawyers who are making their fortunes by them. To our minds, no very revolutionary 
process is needed to render the courts equal to the work. A judge's time in such cases is mainly lost in acquiring the information necessary to enable him to understand the points at issue. On a famous occasion it was said that we should have to educate our masters; litigants in patent cases have to begin by educating their judges. During the course of the Edison case the judge found the evidence on one important point so conflicting, that he suggested the propriety of having experiments made by scientific men on both sides, in the presence of some disinterested man of science, who should report to him on the result. The suggestion was followed : Prof. Dewar and Dr. Hopkinson carried out the experiments on one side, Mr. Crookes and Prof. Silvanus Thompson on the other, the President of the Royal Society being the umpire. In the course of the judgment $\mathrm{Mr}$. Justice Kay acknowledged that Prof. Stokes's report made that "obvious," which he could not previously understand. Prof. Stokes, in fact, was called in quât that particular point as an assessor to the Court. Suppose he had been called in at the beginning, and had sat all through the case, how much time, labour, and unpleasantness would have been spared! How rapidly he would have enabled the judge to narrow down the points at issue, and to understand them! And if Prof. Stokes had been aided by some other independent and qualified man of science, how much sooner and more satisfactorily the whole business would have been concluded. We want, in fact, sworn scientific assessors in courts of justice to aid unscientific judges in arriving with reasonable despatch at reliable conclusions on matters which demand scientific knowledge. Patent cases invariably turn on the construction of a written document--namely, the specification -and this, like all other documents, is a matter for the Court, guided by the rules which apply generally. "But," says Lord Chancellor Chelmsford, "if the terms used require explanation as being terms of art or of scientific views, explanatory evidence must be given, and with this aid the Court proceeds to the office of construction." Now there are two processes already in operation in the High Court of Justice, which it seems to us might well be applied to the determination of these complicated scientific cases, or rather by which disinterested and unbiassed scientific aid might be given to the Court in the determination of cases such as the Edison and Swan case. One is by the system of "referring," the other by assessors. Reference is an every-day proceeding in the Courts in complicated cases. By the 57 th section of the Judicature Act of 1873 , the Courts are empowered "in any cause or matter requiring any prolonged examination of documents or accounts, or any scientific or local examination which cannot, in the opinion of the Court or a judge, conveniently be made before a iury, or conducted by the Court before its ordinary officers, the Court or judge may at any time, on such terms as may be thought proper, order any question or issue of fact, or any question of account arising therein to be tried either befure an official referec, or before a special referee to be ayreed on between the parties." The referee or umpire is armed with proper powers, and in due time reports to the Court, which thereupon proceeds to adjudicate upon the case, having got rid of a mass of technical details with which it was incompetent to deal by the instrumentality of the referee who was quite competent. Doubtless it was in pursuance of this power that $\mathrm{Mr}$. Justice Kay referred a portion of the recent case to Prof. Stokes; but suppose the whole matter, the issues having been narrowed down to their real limits, had been referred at the beginning to Prof. Stokes, aided if necessary by some other independent expert, to report the result to the Court, about twenty days of valuable public time would have been spared, and in the end the decision would have commanded a confidence which the judgment of a wholly unscientific judge, however acute, cannot be expected to receive.

But it appears to us that the system of assessors, who sit with the judge in court, and who aid him with their scientific knowledge and experience, would be even more satisfactory. It is in daily use in Admiralty cases. The practice is thus laid down in Messrs. Williams and Bruce's "Admiralty Practice," second edition, p. 44I :- "If the questions in the cause depend upon technical skill and experience in navigation or other nautical matters, the judge is usually assisted by two of the Elder Brethren of the Trinity House of Deptford Strond, who sit with him as assessors, and who, at the request of the judge, after hearing all the evidence on each side, advise him on all questions of a nautical character. But in all cases it is with the judge alone that the decision rests." An eminent judge of the Privy Council summed up the duty and position of assessors in these words:- " $\mathrm{He}$ (the judge) is advised and assisted by persons experienced in nautical matters; but that is only for the purpose of giving him the information he desires upon questions of professional skill; and having got that information from those who advise him, he is bound in duty to exercise his own judgment. . . The assessors merely furnish the materials for the Court to act upon." But what this comes to in practice, circumscribed though the duties of the assessors are in theory, we learn from a remark of the eminent Admiralty judge, Dr. Lushington: "I never yet pronounced a single decree, when I was assisted by Trinity Masters, in which I was not perfectly convinced that the advice they gave me was correct." The presence of the Trinity Masters is secured by either party filing a pracipe praying for their attendance. And now all Admiralty cases, in whatever Court, may be tried with the aid of nautical assessors, when this is considered desirable.

Although this system is, as a rule, confined to Admiralty cases in practice, all Courts are empowered to call in the aid of assessors, for by the $5^{6 \text { th }}$ section of the Judicature Act of 1873, the High Court or Court of Appeal may in any cause or matter in which it thinks it expedient so to do, call in the aid of one or more assessors specially qualified, and try and hear such cause or matter wholly or in part with their assistance. If Prof. Stokes and some other qualified expert had sat with Mr. Justice Kay during the hearing of the recent lighting case, it is scarcely probable that it would have lasted twenty-cne days, or that various unpleasantnesses inseparable from the hearing of such a case, which was nothing if not scientific, by a conscientious but unscientific judge, would not have been avoided. There are no reasons why a judge should not be aided in cases of this technical description by scientific experts, as Admiralty judges are by nautical experts; there are a great many why he 
should. The orderly and effective administration of justice, the weight which should be attached to judicial decisions, the economy of public time, and, we would add, the self-respect of scientific men, and the best interests of scientific discovery, all call loudly for some such reform as that here suggested.

\section{LANGLEY'S NEW ASTRONOMY.}

The New Astronomy. By Samuel Pierpoint Langley, Ph.D., LL.D. Illustrated. (Boston: Ticknor and Co., I888.)

DROFESSOR LANGLEY'S beautiful book does not appeal merely to the intellect. The senses have their share in the gratification its pertusal affords. Every turning of a page is a conscious luxury. Each touch of the paper, in which the thickness of vellum is combined with the polish of satin, flatters the finger-tips with a bland caress. In texture, it compares with the paper on which ordinary work-a-day scientific treatises are printed as does a velvet-pile with a Kidderminster carpet. The binding is in a corresponding style of lavish magnificence. The illustrations have obtained the last perfection of finish.

Yet the excellence of their execution is for the most part secondary to their intrinsic merit. Needless to say that photographs figure largely among them. There is a capital sunspot series by Rutherford; there are specimens of Pickering's stellar spectra; besides several coronal autographs, Mr. Common's inimitable Orion nebula, and Rutherford's scarcely yet surpassed print of the moon. Among visual delineations, we meet Bond's admirable views of IDonati's comet, Trouvelot's elaborate Saturn, De la Rue's well-known Jupiter, above all, Prof. Langley's own exquisite solar drawings. The surface of the sun has probably never been so perfectly seen as by him ; it has certainly never been depicted with such a wealth of trustworthy detail. Some insight into one of the sources of his success is afforded by the following paragraph (p. 17) :-

"The surface of the sun," he tells us, "may be compared to an elaborate engraving, filled with the closest and most delicate lines and hatchings, but an engraving which during ninety-nine hundredths of the time can only be seen across such a quivering mass of heated air as makes everything confused and liable to be mistaken, causing what is definite to look like a vaguely seen mottling. It is literally true that the more delicate features are only distinctly visible even by the best telescope during less than one-hundredth of the time, coming out as they do in brief instants when our dancing air is momentarily still, so that one who has sat at a powerful telescope all day is exceptionally lucky if he has secured enough glimpses of the true structure to aggregate five minutes of clear seeing, while at all other times the attempt to magnify only produces a blurring of the image. This study, then, dcmands not only fine telescopes and special optical aids, but endless patience."

"Endless patience" is, indeed, a sine quâd non in nearly all departments of astronomy; but it is not always associated with the skill of eye and hand witnessed to by the representations before us. Nor could they have been brought to bear without instrumental accessories of a more than commonly high quality. The polarizing eyepiece made at Pittsburgh must be one of the best ever employed to blunt the keen edge of the solar rays. "By its aid," our author remarks, "the eye can be safely placed where the concentrated heat would otherwise melt iron. In practice I have often gazed through it at the sun's face without intermission from four to five hours, with no more fatigue or harm to the eye than in reading a book."

The object of the work before us is to advocate the claim of the "New Astronomy"-the astronomy which studies the constitution of the heavenly boclies, as opposed to that which determines their movements-to a larger share of public interest, sympathy, and benefactions than has hitherto been allotted to it. The appearance of the eight chapters of which it consists in the pages of the "Century" magazine, has doubtless already contributed to promote that end. They are written in an eminently popular style, and with much of that Transatlantic freshness by which many a jaded European palate is enticed to renewed enjoyment of wholesome literary fare. They profess to give only a sketch of the results so far attained; but it is a highly stimulating and suggestive one. Intelligible to all, they should be welcomed by readers of every grade of culture desiring to gain acquaintance, almost without an effort, with some of the most surprising encroachments ever yet made by the agile human mind upon the vast realms of the unknown.

The two most interesting, because the most original chapters in the book, are those dealing with the "Sun's Energy." Here Prof. Langley is more especially at home; his opinions carry all the weight that long meditation and laborious research can give them; yet they are expressed not only without dogmatism, but almost with diffidence. The higher value given to the "solar constant" by his inquiries into atmospheric selective absorption, have naturally obliged him to curtail the "life" of the sun. During no more than eighteen million years can the present rate of radiation--supposing it fed by the shrinkage through gravity of the sun's substancehave been maintained in the past. "We say "present" rate of radiation," our author continues, "because, so long as the sun is purely gaseous, its temperature rises as it contracts, and the heat is spent faster; so that in early ages before this temperature was as high as it is now, the heat was spent more slowly, and what could have lasted 'only' eighteen million years at the present rate might bave actually spread over an indefinitely greater time in the past; possibly covering more than all the xons geologists asik for."

This is of course perfectly true. There can be no reasonable doubt that the sun was, in the initial stages of its career, a comparatively murky luminary, rich in the promise of future possession, but scantily distributing, because scantily supplied from, stores of light and heat strictly tied up against the possibility of premature waste for the benefit of generations to come, its heirs by entail. But has there been no compensatory period of extravagance? Has our sun already passed through its "Sirian" phase-if a Sirian phase be indeed an inevitable "moment" in the existence of every star-or is it yet to come? The question cannot at present be answered; but until it is, estimates of the probable past duration, 